\title{
DISCURSO PRONUNCIADO POR CÉSAR CAMACHO QUIROZ EN EL DÉCIMO ANIVERSARIO DE LA REVISTA CUESTIONES CONSTITUCIONALES, TOLUCA, ESTADO DE MÉXICO, 5 DE FEBRERO DE 2010
}

Muchas gracias a todos por estar esta tarde en la sede de la máxima casa de estudios de los mexiquenses.

Este acontecimiento académico no se habría podido llevar a cabo en momento más oportuno al conmemorarse hoy, 5 de febrero, la promulgación de la Constitución de 1857, probablemente la mejor Constitución que haya tenido este país; asimismo, al celebrarse la entrada en vigor de la Constitución de 1917, que incorporó las garantías sociales, y ha sido calificada por eminentes juristas como la primera Constitución políticosocial del mundo. Además, no es asunto menor que este encuentro tenga lugar en este espacio, el aula Ignacio Manuel Altamirano de la casi bicentenaria Universidad Autónoma del Estado de México (UAEM), pues la primera Constitución del Estado de México, promulgada el 14 de febrero de 1827 ordenó, en su artículo 228, que en el lugar de residencia de los supremos poderes, habría un Instituto Literario para la enseñanza de todos los ramos de instrucción pública. Así surge nuestra Alma Mater, concebida por el doctor Mora como un centro de enseñanza para los jóvenes republicanos liberales. Así es que hoy convergen el derecho constitucional, el acto fundacional de la UAEM, y el aniversario de la promulgación de dos de nuestras grandes Constituciones federalistas. Espacio y tiempo se convierten en crisol afortunado, y enmarcan este evento de enorme trascendencia para el mundo jurídico y para la universidad pública.

Fue un gran acierto llamarle Cuestiones Constitucionales, a la publicación cuyo aniversario hoy celebramos. Así fue justamente como le denominó a sus "votos particulares" Ignacio L. Vallarta; como llamó a su columna periodística José María Iglesias, cuando se ocupó del análisis del Constituyente de 1857. No hay en esto, por supuesto, ninguna coinci- 
dencia; hay un ejercicio de racionalidad, de inteligencia, pero también de intención, de proyección de futuro. Diego Valadés, entonces director del Instituto de Investigaciones Jurídicas, hace diez años escribía sobre la necesidad de abrir un espacio útil a la reflexión constitucional en México, y por ello nació esta revista, prácticamente un libro, con una visión global, premonitoria, porque si hoy México no es una ínsula, menos lo será en los próximos años. De esta suerte, la revista-libro ha dado cabida, como expresión de lo que yo llamaría "democracia intelectual", lo mismo a reflexiones de Peter Häberle, que de Luigi Ferrajoli; de Ronald Dworkin, de Gustavo Zagrebelsky o de Robert Alexy. Junto con ellos, han ocupado espacios destacados, muchos autores mexicanos que, con enorme orgullo para todos nosotros, han formulado interesantes aportaciones, o se han ocupado de las nuevas tendencias del mundo del derecho, no adoptando, sino adaptando a la cultura jurídica nacional, a las necesidades contemporáneas, los modelos y las ideas extranjeras que, por supuesto, suelen ser respetables, interesantes y muchas veces útiles.

Desde "La jerarquía constitucional de los tratados" de Edgar Corzo, hasta "Los instrumentos constitucionales para el control parlamentario" de Cecilia Mora-Donatto, o la disquisición sobre "El sistema presidencial o parlamentario" de Jorge Carpizo, lo que ha hecho Edgar Corzo es ofrecer un espacio para ejercer el "derecho a disentir", pues se dice con acierto que en el derecho, no siendo una disciplina exacta, nadie tiene la razón ni carece de ella absolutamente.

Qué mejor que con los medios y las técnicas más avanzadas, al alcance de todos, tengamos la oportunidad de descubrir conceptos y de confrontarlos con los propios; de interpretar planteamientos y propuestas, para adoptar o recrear aquéllos que mejor describen o pretenden modificar positivamente la realidad política y social del país. Es muy grato encontrar una publicación que no es "sólo para iniciados", pues no se requiere forzosamente un estudio especializado para abrevar de ella; es decir, que no está hecha sólo para académicos o especialistas, legisladores y jueces, sino para quienes consideran que la sociedad puede ser mejor, merced al derecho y la justicia. Qué importante es advertir que la revista no instaura, ni lejanamente, un cenáculo de diletantes jurídicos; más bien, abre un espacio para que quien tenga una opinión nueva y diferente, la exponga, la coloque en una mesa de discusión y la someta al escrutinio de los demás. 
Es lectura obligada porque ofrece un andamiaje, una edificación que propicia la oportunidad para hacer planteamientos y la convierte en caja de resonancia para proveer elementos de discusión a quienes más temprano que tarde toman decisiones. Es un espacio donde el binomio inseparable de sociedad y derecho, tienen la oportunidad de coexistir a fin de que el derecho sirva a la primera en la concreción de los anhelos de quienes viven en comunidad.

Es una buena oportunidad para que una universidad de arraigada tradición liberal y comprometida con las causas nobles, por medio de su Facultad de Derecho que, por cierto, nació junto con la universidad, el entonces Instituto Literario, haga un merecido reconocimiento al Instituto de Investigaciones Jurídicas dedicado al estudio, a la enseñanza y a la divulgación de la ciencia jurídica.

La experiencia profesional acumulada en diversos espacios del quehacer público, me enseña que en un Estado democrático de derecho, la norma jurídica es indispensable, no sólo apetecible; que no sólo se nutre de la realidad, sino trata de transformarla y convertir aspiraciones colectivas en proyectos institucionales. Me consta que cuando el Instituto de Investigaciones Jurídicas se pronuncia, marca la pauta, cala hondo y se convierte en una referencia obligada, cuando se trata de resolver conforme a derecho; si el reto es construir espacios, oportunidades o andamiajes jurídicos para fortalecer a la democracia, para hacerla más eficaz, esta respetable institución estará atenta para hacer su republicana aportación.

A Héctor Fix-Fierro, heredero y custodio de una larga tradición; setenta años desde aquel antiguo Instituto de Derecho Comparado hasta el hoy Instituto de Investigaciones Jurídicas, orgullo para todos quienes somos parte del alma mater nacional, le ha tocado hacer eco de las complejas discusiones jurídicas contemporáneas. En las convocatorias del Senado, de la Suprema Corte, de los tribunales locales o en la recientemente discutida reforma constitucional al sistema de justicia penal, el Instituto de Investigaciones Jurídicas ha jugado un papel trascendente y notable. Por ello, en este episodio, al doctor Héctor Fix-Fierro y a los más de cien investigadores que forman parte de su claustro, les expresamos gratitud, reconocimiento y el deseo fraterno de larga y fructífera vida institucional.

A Edgar Corzo, felicidades, porque desde que inició la conducción de Cuestiones Constitucionales, no sólo comparte sus opiniones, no sólo dirige con éxito la revista, sino reconoce el trabajo de los investigadores, exige calidad a quienes la publican, y constata la importancia que tiene 
el análisis del acontecer diario a la luz del derecho constitucional, sin dar cabida a la improvisación. Y ahora le digo, echando mano de una expresión frecuente en él: "aviso de caminante", los retos serán más grandes en el futuro inmediato.

Pues bien, el surgimiento del derecho constitucional se da por una necesidad: por hacer que prevalezcan las instituciones y las leyes frente a las personas. Es el higher law, el derecho más alto, en ese Estado constitucional; la dignidad de las personas y de los ciudadanos, como dice Peter Häberle, son la premisa antropológica y cultural. La Constitución, por tener presente a Fernando Lasalle, deja de ser la suma de los poderes fácticos, y se considera, ahora, en letra de Zagrebelsky, el conjunto de normas, valores, principios y directivas, e incluyendo a Dworkin, surge la necesidad de hacer una lectura moral de la Constitución; es decir, no considerarla un conjunto de normas jurídicas, sino la síntesis, la quintaesencia de los valores de las personas convertidos en normas jurídicas. La Constitución, pues, es el broche de una larga cadena de eslabones que se refieren a los derechos humanos, a la interpretación, a la constitucionalidad de los actos de las autoridades y de la ley.

Es tan importante el derecho constitucional que, de los casi 200 países reconocidos formalmente por el sistema de Naciones Unidas, 93 han promulgado Constituciones nuevas o han hecho reformas sustanciales; es decir, prácticamente la mitad de los países del orbe gozan de una nueva Constitución o se esmeran en robustecer su constitucionalidad. Esto me permite afirmar que no sólo vivimos una época de cambio, sino un cambio de época; eso que los aztecas consignaban en la cuenta larga de la historia. Este periodo no se va a registrar como el tiempo ordinario de la humanidad, sino como un tiempo singular en el que hubo cambios vertiginosos, en el que acontecieron hechos, sucesos que marcaron a las personas, a los pueblos y por tanto a las instituciones.

Las fronteras son, en algún sentido, un asunto virtual. En estas condiciones, estamos viviendo nuevos tiempos para todos, nuevas actitudes y nuevos desafíos. En México, en donde no podemos sustraernos a estos hechos, de la mano de Carlos Fuentes sostengo que vivimos un "nuevo tiempo mexicano" que nos está demandando, con urgencia, cambios radicales, no sólo cambios de visión, sino cambios de actitud y, asumiendo la parte de responsabilidad que nos toca a algunos, la volatilidad del derecho constitucional parece no ayudar. La Constitución, con sólo 136 artículos ha tenido casi 500 transformaciones y uno solo de ellos, el 73, 
más de setenta. Esto dificulta la labor de los especialistas, decía el propio Valadés al escribir en el primer número de Cuestiones Constitucionales, que sobran constitucionalistas capaces de escribir un tratado de derecho constitucional, quienes corren el riesgo de que cuando lo concluyan, éste haya perdido actualidad porque probablemente nuevas reformas estén en vigor y, por tanto, ya no suscite el mismo interés.

En síntesis, México enfrenta hoy retos de grandes proporciones, que demandan de todos, pero subrayadamente de quienes tenemos responsabilidad y apetito por estos trascendentes asuntos, una actitud resuelta y una asunción de compromisos. Desde la academia, la docencia, desde el ejercicio de la autoridad o, sencillamente, por la familiaridad con los grandes temas constitucionales, debemos fijar posición e impulsar las transformaciones necesarias.

Algunos asuntos al desgaire:

I. Es urgente un replanteamiento de las relaciones entre poderes: el "telón de fondo", esto es, el entorno en el que se desempeñaban el Legislativo, el Ejecutivo y el Judicial no es el de hace veinte años; igualmente se requiere rehacer el trato político entre Federación, estados y municipios, es decir, discutir y, seguramente replantear, el pacto federal. Se ha acabado el poder hegemónico del centro; esa fuerza omnipotente y omnipresente debe dar lugar a una necesaria coordinación entre poderes, de manera horizontal, y entre ámbitos de gobierno, por lo que hace a la vertiente vertical.

II. La sociedad exige, y con razón, a quienes tienen la oportunidad y, a la vez, la responsabilidad de ocupar responsabilidades públicas, una actuación transparente y una actitud dispuesta a rendir cuentas, pues el ejercicio de la autoridad se hace a nombre de la gente. Los asuntos públicos deben ser, cada vez más públicos.

III. Se necesita una mayor equidad en el terreno hacendario, no sólo para ejercer el gasto, sino para desarrollar eficazmente la siempre ingrata tarea de recaudar, habida cuenta que de la mano de la prerrogativa de aplicar recursos públicos, debe ir la responsabilidad de hacerse de ellos.

IV. Es impostergable la vigencia cabal del nuevo sistema de justicia penal, que a la vez que respete los derechos y garantías de todos los involucrados en la investigación, sea eficaz en el combate al crimen organizado; que haga ágil y transparente cada asunto penal, que no criminalice la pobreza, que proteja a la víctima y que castigue al verdadero culpable, 
para recuperar la confianza ciudadana en las instituciones de procuración y administración de justicia.

V. La intervención de la ciudadanía en la vida pública debe ser creciente; por ello, nunca sobran los mecanismos o instrumentos destinados al efecto. Además del valor intrínseco de sus opiniones y propuestas, tarde o temprano, los ciudadanos suelen ser destinatarios de toda reforma; adicionalmente su participación contribuye a la gobernabilidad y es fuente de gobernabilidad.

VI. La exigencia de un Estado constitucional cuyas premisas sean el respecto por los derechos humanos, por los valores de la democracia y por el ejercicio de los controles del poder público, que permita difundir la importancia el valor que tiene la Constitución no sólo como norma primigenia y garantista, sino como la columna vertebral de nuestro sistema jurídico.

Como se advierte, por ésas y muchas más razones, la existencia de Cuestiones Constitucionales, no sólo es importante, es indispensable. Por una parte, debemos ventilar públicamente lo que se discute al interior de la academia y, si fuera el caso, darle forma jurídica a las aspiraciones colectivas. Quien tiene el acierto de escuchar, tiene la posibilidad de equivocarse menos; en consecuencia, insto de manera respetuosa aunque resuelta, al Instituto y a Edgar Corzo, para hacer más amplia la difusión y para ensanchar los espacios de participación en Cuestiones Constitucionales. Para que se democratice la discusión; para que no sea un asunto "sólo para iniciados" en el derecho constitucional, sino, con todo el cuidado, para mantener el prestigio de la publicación, darle cabida a las voces que, como las muchas que hay en México, tienen cosas muy importantes que decir.

Desde ese México profundo, como lo describía Reyes Heroles, hay infinidad de asuntos que plantear y muchos compromisos por asumir; para lograrlo, se requieren varias cosas, aunque dos centralmente: se necesita pericia, es decir, claridad conceptual, manejo del tema; pero, sobre todo, voluntad, entusiasmo, ganas de hacer las cosas, deseos de transformar el entorno, voluntad para hacer bien lo que está al alcance de cada uno. Se ha dicho, hasta el cansancio, que cada crisis es una oportunidad y si alguien sabe de crisis somos los mexicanos de esta generación. En consecuencia, transformemos los desafíos en oportunidades y encontremos, en espacios como Cuestiones Constitucionales, el sitio para aprovecharlas. 
Tenemos la mejor opción, el mejor motivo: el Bicentenario del inicio de la Independencia de México. Los seres humanos somos disímbolos y, hoy, en el país vivimos un momento que se repetirá hasta dentro de muchos años. Echemos mano de esta celebración y convirtámosla en acicate y elemento de unidad entre los mexicanos, porque más allá de filias y fobias transitorias que tienen que ver con la ideología partidaria o con los credos religiosos, la patria envuelve, da oportunidades y nos compromete a todos. Conmemorar es hacer un ejercicio de memoria en común, pero la mejor oportunidad para conmemorar, es relanzar al país hacia mejores estadios, con la certeza que conseguiremos buenos resultados si lo hacemos todos, más aún si lo hacemos juntos, en equipo, que es, por cierto, como mejor resultan las cosas. 